\title{
Antecedentes de la psicología deportiva en España. La posición de César Juarros
}

\section{Historical background of Sport Psychology in Spain. The position of César Juarros}

XAVIER TORREBADELLA-FLIX

Departamento de Didáctica de la Expresión Musical, Plástica y Corporal. Facultad de Ciencias de la Educación. Universidad Autónoma de Barcelona. España

franciscoxavier.torrebadella@uab.cat

ORCID: http://orcid.org/0000-0002-1922-6785

\section{JOAN ESTRADA-AGUILAR}

Departamento de Didáctica de la Expresión Musical, Plástica y Corporal. Facultad de Ciencias de la Educación. Universidad Autónoma de Barcelona. España

joan.estrada@uab.cat

ORCID: https://orcid.org/0000-0003-3812-8010

Recibido: 19-11-2019. Aceptado: 27-09-2020.

Cómo citar / Citation: Torrebadella-Fix, X. y Estrada-Aguilar, J. (2020). Antecedentes de la psicología deportiva en España. La posición de César Juarros, Ágora para la Educación Física y el Deporte, 22, 18-42.

DOI: https://doi.org/10.24197/aefd.0.2020.18-42

Resumen: En este artículo se presenta la posición ideológica que el doctor César Juarros adoptó sobre el concepto de educación física y deporte y, en especial, sobre la problematización de la educación física infantil durante el primer tercio del siglo XX. La polémica se muestra en un momento crítico de auge de la gimnástica sueca y de la institucionalización deportiva en España. Una metodología histórica y de análisis documental de fuentes primarias de este autor posibilita descubrir su pensamiento crítico, que se instala en España como la primera intervención académica desde la psicología social, el psicoanálisis y la criminología. Como veremos, cien años después, la posición de Juarros no dista mucho de cierto pensamiento crítico actual.

Palabras clave. Deporte infantil; educación física; psicología social; historia; psicoanálisis.

Abstract: This article presents the ideological position that Dr. César Juarros adopted on the concept of physical education and sport and, in particular, on his problematization of children's physical education during the first third of the 20th century. The controversy takes place at a critical moment of the rise of Swedish gymnastics and sports institutionalization in Spain. A historical methodology and documentary analysis of primary sources of this author makes it possible to discover his critical thinking, which is considered in Spain as the first academic 
intervention from the fields of social psychology, psychoanalysis and criminology. As we shall see, a hundred years later, Juarros' position is not far from certain current critical thinking.

Keywords: Children's sports, physical education, social psychology, history, psychoanalysis.

\section{INTRODUCCIÓN}

Desde mediados del siglo XIX, la educación física escolar se configuró amparada por la narrativa higiénico-médica que vinculaba la dominación de la voluntad a través de la dominación corporal. La pedagogización sexualizada de los juegos de la infancia, la aplicación de una profiláctica gimnástica sueca o, también, el considerar la gimnástica como dispositivo antionanista, componían parte de un imaginario colectivo que asociaba irracionalmente las malas costumbres a la degeneración social y a la decadencia humana (Torrebadella-Flix y Vicente-Pedraz, 2016). Así, en el campo escolar sobre la infancia se articularon modelos educativos con el objeto de encauzar la docilidad y la obediencia de la clase obrera, con lo cual se sublimó la uniformidad metódica de la gimnasia sueca como dispositivo disciplinar en el control psicológico y la intervención de una medicina social (Torrebadella y Brasó, 2017). Asimismo, surgió algún que otro proyecto que trató de educar a través del fútbol a una infancia desprotegida y "peligrosa" (Torrebadella-Flix, 2017a).

En España, el despertar finisecular de la conciencia regeneracionista puso en acción las tesis de una corriente gimnástico-deportiva, cuyo colectivo de representantes repercutió en una generación del '98 de cuño propio, que se movilizó en nombre de la llamada regeneración física (Torrebadella, 2014). En esta coyuntura, la aparición del deporte estuvo ligada al desarrollo de la educación física escolar en los elitistas colegios de las congregaciones religiosas de principios del siglo XX. De estos colegios surgió el deporte como elemento de modernidad e impulsó el primer movimiento de masas del asociacionismo juvenil, pero también coadyuvó a forjar los códigos disciplinares de un sistema de escolarización burgués. Singularmente, la educación física en estos colegios puso la emulación de las prácticas deportivas como uno de los pilares ideológicos y modelo de distinción de la calidad educativa. Si bien, la otra educación física, aquella que debía fraguarse en la instrucción de los hijos de la clase obrera en las escuelas públicas, quedó 
prácticamente desatendida y, cuando no, atendió a una rudimentaria y simple, pero disciplinada gimnasia higiénica; la educación física de los colegios privados seguía otros derroteros a expensas del deporte y especialmente del fútbol (Torrebadella-Flix y Vicente Pedraz, 2017).

Ahora bien, de todos los juicios formulados por las autoridades médicas en el campo de la educación física infantil se destacó, en particular, la opinión del doctor César Juarros. Precisamente se verá que, durante el primer tercio del siglo XX, las opiniones de este doctor contribuyeron a configurar un discurso crítico que marcó una significativa influencia en el campo de la pedagogía y la psicología infantil.

El objetivo de este estudio es dar a conocer, en una exposición preliminar, la posición que adoptó el Dr. Juarros en el campo de la educación física y el deporte durante el primer tercio del siglo XX. Además, se pretende reposicionar a Juarros como pionero crítico en temas actuales referidos a la educación física, la especialización deportiva, la salud y la pérdida de valores educativos del deporte de élite, entre otros aspectos. Igualmente, se aborda la polémica que subyace en un momento histórico en el cual se aceptó públicamente la gimnástica sueca y se inició una progresiva institucionalización deportiva, y cuyas influencias se dejaron sentir en la educación física escolar.

\section{Metodología}

En lo relativo al estado de la cuestión y a la naturaleza del estudio que aquí se plantea, los trabajos centrados en la figura del Dr. Juarros, y el carácter polifacético de su vida profesional (literato, psicoanalista, publicista, dirigente deportivo, político...), aún son escasos y frecuentemente surgen en el ámbito de historia de la psicología (Samblás, 2002, 2004, 2008). En cuanto a la educación física y el deporte, el Dr. Juarros solamente se trata en los trabajos de Torrebadella (2012) y Torrebadella-Flix y Domínguez (2018a y 2018b). Por todo ello, el estudio es una aportación inédita que abre una vía de investigación en cuanto al análisis de las divergencias y afinidades en torno al desarrollo de las ideas y posiciones doctrinales en la historia de la educación física y el deporte.

La elección metodológica es de fondo histórico y naturalmente viene sustentada por una localización previa de las fuentes documentales (heurística). El alcance de esta fase es amplio y contiene tres líneas de 
búsqueda. En primer lugar, se atiende a la revisión bibliográfica de los estudios precedentes utilizando recursos documentales propios (Torrebadella, 2011; Torrebadella-Flix, 2017b). Luego se atiende a otra revisión bibliográfica sobre los estudios pertinentes o relacionados con el señalado autor y el objeto de estudio. En tercer lugar, se buscan las fuentes originales del autor. En este punto se utiliza la Biblioteca Nacional y las hemerotecas digitalizadas de la prensa histórica principalmente de la Biblioteca Nacional-. En una segunda fase se procede a la selección de los textos diana, en cuanto que desvelan el pensamiento crítico del autor y ponen en juego la problematización ideológica de la educación física y el deporte en el momento histórico. Por último, se procede a la triangulación hermenéutica del discurso o cuerpo del artículo que, en cierto modo, tiende a autorizar la continuidad de las ideas del Dr. Juarros.

\section{Algunos datos Sobre CÉsar Juarros}

César Juarros Ortega (Madrid, 1879-1942) [figura 1], Licenciado en medicina en 1903, ingresó en el Cuerpo de Sanidad Militar y alcanzó el grado de médico Mayor del Ejército; se especializó en psiquiatría y desempeñó sus conocimientos en el campo militar e infantil. Sus múltiples facetas médicas, periodísticas e intelectuales le llevaron a la Real Academia de Medicina en 1928 y Diputado a Cortes en la II República -por la Derecha Liberal Republicana y luego por el partido Republicano Progresista-. En el ámbito profesional de la neuropsiquiatría desplegó una intensa actividad interviniendo acerca de las enfermedades nerviosas, toxicómanas, discapacidades psíquicas, etc., y también se preocupó de la educación sexual infantil -de los niños y niñas-, ya en el entorno familiar como en el escolar, la higiene pública y la educación física escolar. Juarros desplegó argumentos del psicoanálisis y adoptó técnicas de práctica clínica, por lo que se destaca como uno de los más significativos representantes de las teorías freudianas en España (Del Cura y Huertas, 2004; Lévy, 2016). En la faceta literaria publicó numerosos manuales de texto y una infinidad de artículos de divulgación científica. Sin duda fue una de las autoridades médicas con más actividad en la segunda y tercera década del siglo XX. En 1924 fue nombrado médico director de la Escuela Normal Central de Anormales y profesor de Psiquiatría en el Instituto Español Criminológico de Madrid. Como 
seguidor del psicoanálisis, representó una significativa opinión en los intentos de las reformas educativo-sexuales (Diego Pérez y González Fernández, 2014; Huertas y Novella, 2013; Samblás, 2004).

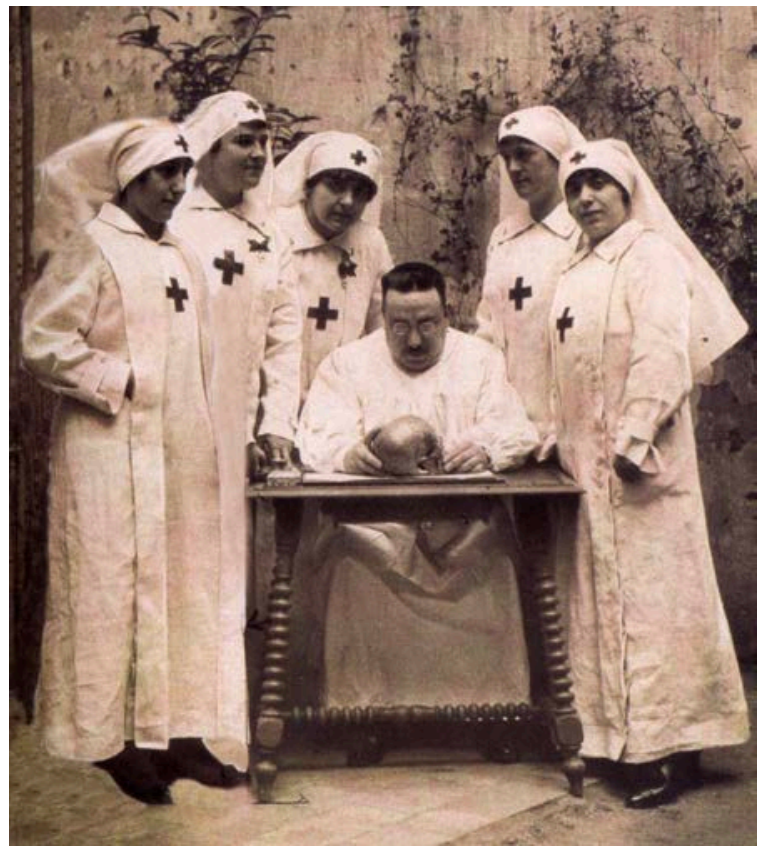

Figura 1. Dr. César Juarros Ortega. (Fuente: Real Academia Nacional de Medicina)

En cuanto a la educación física y el deporte, se destacó como articulista y colaboró en importantes revistas: La Jornada Deportiva (1921-1925), Aire Libre (Madrid, 1923-1925), El Campeón (1932-1936) y Gimnástica (Madrid, 1934-1936). Además, también fue un destacado dirigente deportivo. En 1924 fue nombrado presidente de la Sociedad Cultural Deportiva y, en 1933, fue elegido presidente de la Confederación Gimnástica Española. Publicó algunas obras higiénicopedagógicas: Educación física y moral del niño (1918), La crianza del hijo (1919), Significación y alcance de las inspección médico-escolar (1919) y Normas de educación sexual y física (1925). También sobresale su faceta de novelista con numerosas obras. De todas ellas hay que destacar El niño que no tuvo infancia (Juarros, 1927a), donde trata la educación infantil y el problema erótico, y describe el ambiente del bullying escolar (Cansinos, 1928). 
Juarros estuvo influenciado por las ideas eugenésicas y neomaltusianas; participó a primeros de 1919 en la creación del Instituto de Medicina Social, institución vinculada principalmente al Dr. Antonio Aguado Marinoni (Álvarez Peláez, 1988). De aquí surgieron estudios relacionados con las condiciones de la clase obrera, es decir, esos dos tercios de la población española que tanto preocuparon al Dr. Andrés Martínez Vargas (1918) cuando argumentaba la defensa de la raza española.

\section{JUARROS Y LA DISYUNTIVA PSICOPEDAGÓGICA EN EL DEPORTE}

\subsection{Sobre el concepto de psicología del deporte}

En 1900 es la primera vez que aparece en la prensa española el concepto de "psicología del deporte". El responsable fue el mismo Pierre de Coubertin, en un artículo titulado "La psicología del deporte”, que presentó en la Revue des Deux Mondes, en julio de 1900 (Coubertin, 1913). No obstante, como trata Horthous (2015), Coubertin desarrolló un campo de estudio muy diferente al concepto moderno (Pérez y Estrada, 2015).

La psicología del deporte, por P. de Coubertin. No son ya los ejercicios físicos un monopolio de Inglaterra; hoy se juega en todas partes y por gente de todas edades. Divide el deporte en dos grupos: de equilibrio y de combate. Expone sus observaciones personales acerca de cada uno de ellos, y dice que la característica psicológica del juego es su tendencia al exceso. (Revista de revistas, 1900, p. 13).

En 1913 el concepto volvió a ser utilizado en el Congreso Internacional Olímpico de Lausana (llamado Congreso de Psicología Deportiva, del 7 al 11 de mayo). Aquí Coubertin (1913) se ocupó de los «Ensayos de psicología deportiva» -una recopilación de artículos publicados en la Revue Olynpique entre 1906 y 1912-, los cuales "bosquejaban casi todos los problemas de psico-fisiología atlética" (R. S., 1913, p. 1). A este congreso también asistió el profesor de educación física Marcelo Sanz, como delegado oficial por España, y comentó que "las tareas del Congreso tuvieron por objeto bautizar una ciencia, la Psicología deportiva, cuyos dominios son todavía desconocidos; la misma Fisiología deportiva, que también fue objeto de discusión, con ser 
más conocida, está poco manoseada” (Sanz, 1913a, p. 6). Asimismo, Sanz aprovechó para censurar el estado de la educación física en España y hacerse una pregunta: “¿Cómo, faltando la base de una educación racional, hemos de comenzar por los deportes? He aquí nuestras dudas ante los nuevos rumbos de la educación física” (Sanz, 1913b, p. 4).

Para Coubertin (1913), la piscología deportiva era la influencia que las diferentes prácticas deportivas ejercían sobre la configuración del carácter; una influencia que, si bien no afectaba directamente a la formación de la moral, sí que a través de ella se podía intervenir en el ámbito pedagógico, con el propósito de aprovecharla en un sentido u otro.

Este Congreso, que trató sobre el influjo del deporte en el individuo y la sociedad, puso de relieve la transcendencia en orientar una pedagogía deportiva que no se desviase hacia otros derroteros, como años después denunció George Hébert (1925), y que Coubertin (1925) trató de redefinir nuevamente en Lecciones de pedagogía deportiva.

Ahora bien, en España, el Dr. Juarros ya se ocupaba de trasladar en el campo pedagógico y social la influencia que ejercía la educación física y deportiva sobre las personas y el carácter generalizado de la población. Así sentenciaba el estado del problema: "En España donde se carece de educación física, los hombres no conducen su vida; se dejan conducir por ella” (Juarros, 1916b, p. 7). Efectivamente, Juarros atribuía a la acción de la educación física la capacidad de influir en el carácter, es decir, en la relación que se establece con aspectos positivos sobre el dominio de la voluntad:

Nada hace tan sombrío, tan tímido, tan desmontado, tan susceptible, como la carencia de dominio de nuestros músculos. El no saber usarlos, el no tener confianza en su eficacia, nos coloca en un plano de inferioridad respecto a los demás, sin otra solución compensadora que la envidia, o la malicia, o la desconfianza.

¿Quién no conoce el extraño estado psicológico que crea un traje dentro del cual no nos encontramos cómodos? (Juarros, 1916b, p. 7)

\subsection{Juarros y el concepto de educación física}

Ahora bien, Juarros proporcionó un pensamiento crítico ante el modelo deportivo, que a partir de la tesis de Coubertin (1925) trataba de 
imponerse en el entorno infantil y escolar. Como veremos, esta posición de Juarros marcó una disyuntiva psicopedagógica en el deporte.

Con motivo del Primer Congreso Nacional de Educación Física, Juarros (1916b) se comprometió a publicar artículos de divulgación en su apoyo (Ruiz-Ferry, 1917). En estos artículos reflexionaba sobre el concepto de educación física. Advertía que la educación física no consistía en el acrobatismo gimnástico, ni en hacer atletas, ni tampoco en el cultivo de los deportes. Pensaba que este Congreso había de contribuir a dilucidar la "creación de un método español de educación física" (Juarros, 1916c, p. 3), con lo cual aparecía cierta obsesión para naturalizar una forzada orientación hacia una educación física de carácter nacional: "Cada país necesita de un sistema de educación física apropiado a las condiciones de su raza. Sería una vía peligrosa la de limitarse a poner en castellano textos suecos" [...] y, por lo tanto, “el querer importar un método exclusivo, radicalmente, equivaldría a ir al fracaso" (Juarros, 1916c, p. 3).

En otro artículo, Juarros (1916a) censuró la ignorancia que comúnmente existía al confundir el verdadero objeto de la educación física con el exhibicionismo estético, frívolo y romántico de la gimnástica acrobática y el deporte. La posición de Juarros estaba comprometida con el medular regeneracionismo del momento e interpelaba profundamente a una cuestión de preocupación nacional: "Nuestra raza resulta de una debilidad física que aterra, que llena de rabia y hace germinar la impaciencia". Por lo tanto, aprovechando la oportunidad de propaganda del Congreso, Juarros (1916a, p. 3) se comprometía a "la regeneración física de España", es decir, a reparar a "la juventud enclenque, enfermiza, raquítica" de la "miseria fisiológica" y que se evidenciaba en el reclutamiento militar.

Aun así, al margen del Congreso -que nunca se realizó- Juarros continuó dedicándose a la divulgación psicopedagógica de la educación física. Sobre este asunto su aportación crítica incitaba un debate permanente: "La educación física, como la intelectual, como la moral, ha de someterse siempre a las condiciones del sujeto. El obligar a los individuos a ajustarse a patrones generales es un delito de lesa humanidad” (Juarros, 1916a, p. 3). 


\subsection{Las discusiones sobre la educación física y sus métodos}

En la Sociedad Cultural Deportiva Juarros expuso su opinión el método natural de George Hébert (1875-1957), al que presentó como el mejor de cuantos hasta entonces se habían conocido. Este momento coincidía cuando la gimnasia sueca empezaba a ser cuestionada por su baja eficacia en el campo de batalla y el deporte se erigía en el ejército francés como el revitalizador físico y moral de las tropas en la Primera Guerra Mundial (PGM) (Torrebadella, 2016). No obstante, en España, la gimnasia sueca se presentaba como el mejor sistema de educación física: higiénico, racional y democrático, es decir, al alcance de toda la población. Pero para Juarros, "el método Hébert, reglamentario en la marina francesa, es mucho más conveniente para nosotros, si bien, añadió, que, a pesar de las excelencias de este método, debemos los españoles procurar hacer un método nacional” (Noticias, 1917, p. 190).

Las opiniones de Juarros fueron recogidas por la prensa deportiva y generó una corriente favorable al método de gimnasia natural. Juarros declaraba que había que crear "un sistema de educación física, de gimnasia, que no consista en la simple traducción de uno u otro método extranjero: precisa una gimnasia española para los españoles” (RuizFerry, 1917, p. 96). Insistía en el asunto, que en España no se podían copiar, sin más, los sistemas de gimnasia y deportes como el fútbol creados para otras latitudes y razas, y más apropiados para temperamentos fríos y disciplinados; opinaba que "el carácter español exigía juegos españoles” y que por nuestro individualismo no podríamos jamás brillar en estos deportes extranjeros.

\subsection{La educación física y la formación del carácter}

En cuanto a la pregunta: “¿hasta qué punto puede resultar sensato pensar que la educación física es capaz de contribuir a reformar la infancia rebelde o delincuente?” (Juarros, 1917, p. 4), la respuesta era contundente. Sí, la educación física y la gimnástica metódica era necesaria en todos los reformatorios, aunque:

no debe deducirse que la educación física pueda bastar «por sí sola» en todos los casos para reformar a un rebelde. Lo que hace la educación física es facilitar dos cosas esencialísimas para un régimen de buena conducta: la confianza en sí mismo y la facilidad para el esfuerzo. (Juarros, 1917, p. 4). 
Todas estas aportaciones se incorporaron en un trabajo premiado por el Legado Roel (Juarros, 1918), donde se indicaba la ineficacia educativa escolar. Advertía a los padres que la escuela, por sí sola, no podía cumplir su función sin la ayuda de las familias. La educación debía atenderse en el hogar y la instrucción en la escuela. Sostenía que educar no es otra cosa que crear hábitos, aspecto que primeramente debería empezar por entender la psicología infantil. Eso suponía que los niños no podían recibir la educación autoritaria y punitiva que era tradicional en las familias. Aquí se dejaba sentir la influencia del pedagogo John Dewey (1850-1952) y, al respecto, opinaba que los padres tenían que considerar la influencia del ambiente y las amistades que se desarrollaban en la infancia.

Juarros apuntaba el taylorismo como método, en un sentido de orden, de programación de las tareas y el tiempo, es decir, de los esfuerzos cotidianos, de sistematizar rutinas de trabajo, eso sin caer en el automatismo y permitiendo cierta flexibilidad y atendiendo a las diversidades de caracteres. Otro aspecto era el del ejercicio físico, por supuesto bajo el método natural de Hébert, es decir, dejando autonomía al niño para desarrollar el movimiento espontáneo, "con absoluta libertad, sin cortapisas ni engorros (Juarros, 1918, p. 40); o sea, sin necesidad de auxilio técnico alguno y menos de gimnasios, pesas y de tablas de ejercicios mecanizados. El único problema era el reto que tenía el adulto en estimular convenientemente el ejercicio natural. Sobre esta cuestión recurría a las orientaciones metodológicas de los juegos propuestos por Edouard Claparède (1873-1940), que buscaban la curiosidad del niño, la afectividad del mundo sensitivo, la creatividad, el desarrollo de las emociones y el fomento de la investigación científica. En esta orientación no descartaba el tradicional juego de pelota vasca, los juegos de lucha o el juego del marro que los consideraba muy superiores a los deportes.

De aquí que Juarros propusiese actuar sobre la infancia como antídoto preventivo de la degeneración y la delincuencia, es decir, utilizar la escuela como dispositivo al servicio de una medicalización social que había de revertir en una educación intelectual, moral, sexual, estética y física. 


\subsection{La crítica al modelo deportivo}

Así pues, la irrupción de Juarros en plena PGM y cuando el deporte estaba demostrando en los países beligerantes sus efectivas propiedades morales y combativas, fue una aportación bien recibida. En España, las voces expertas que criticaban la pobreza de la condición física de los jóvenes no consideraban que biológicamente se tuviese que seguir un modelo de educación física cuando el país aún no estaba preparado. Las potencias que participaban en la PGM adelantaban a España en fortaleza física, esta era una convicción que desde décadas se venía tejiendo en el imaginario colectivo de aquellos que apelaban a la educación física y a la regeneración física de la raza española.

Las palabras de Juarros eran más que controvertidas, atacaban al dispositivo de masculinización que la PGM había creado para la construcción nacional de los estados (Mosse, 2000). Así citaba Juarros (1918, p. 34): "El culto excesivo al deporte desintelectualiza la vida. Fomenta el culto irrazonado a la fuerza. Llena de vanidad al fuerte y de despecho al débil” [...] "El deporte no educa físicamente y sí deseduca moralmente".

Sobre estas afirmaciones Juarros no tardó en sentenciar al deporte como causa de enfermedad: "Los deportes no educan ni física ni intelectualmente. Entretienen y crean hábitos de empleo de ciertos grupos musculares, establecen nuevas vías de asociación, automatizan movimientos complicados, pero no hacen educación física” (Juarros, 1919, p. 15).

A pesar de las oposiciones, Juarros empezaba a ser considerado un "prestigioso apóstol de la educación física” y abordaba aspectos sobre la “Anatomía y Psicología del Deporte”, para orientar el perfecto desarrollo psicofísico (P. P., 1919, p. 6).

Si bien se ha citado que la psicología del deporte empieza en 1919 después de la PGM-, es también a partir de esta fecha cuando en España se descubren intervenciones divulgativas de Juarros que se ocupan de la "Psicología del Deporte” (Discóbolo, 1919; P. P., 1919) o bien de la "Psicología del deportista” (Juarros, 1927c, 1927d).

Durante los años veinte, en España el deporte experimentó una extraordinaria expansión. En este momento confluía una coyuntura exterior a través del auge del deporte internacional de postguerra y las correspondientes políticas de protección que desarrollaron las potencias participantes y, en la coyuntura interior, el efecto "furia española”, tras el 
éxito de la Selección del fútbol en los JJOO de Amberes. La educación física también entró en el cuartel y la Escuela Central de Gimnasia (1919-1936) puso en marcha una promoción deportiva entre los jóvenes de clase obrera (Torrebadella, 2019).

El compromiso de Juarros con la educación física tuvo su punto álgido en 1924, al convertirse en presidente de la Sociedad Cultural Deportiva (SCD), una de las entidades juveniles más emblemáticas de Madrid. En los campeonatos castellanos de atletismo de este año después de los JJOO de París- se destacó la ausencia de la SCD, que decidió unánimemente no participar: "el Dr. Juarros, que ha impuesto su autoridad de fisiólogo, y que no permite que los muchachos de su Club destrocen, caprichosamente, su salud dedicándose a deportes para los que no están preparados físicamente” (Ruiz-Ferry, 1924, p. 466).

El director del Heraldo Deportivo, Ricardo Ruiz-Ferry (1924), felicitaba esta decisión por oportuna, puesto que hacía años que solicitaba que todos los deportistas pasaran la debida inspección médica, tal y como aconsejaban las autoridades en la materia. Así, la decisión de la SCD representaba una protesta para encauzar una saludable práctica deportiva sin riesgos: "Ojalá imiten a Juarros y a la «Cultural» todas las asociaciones españolas que vienen dedicándose a la propaganda deportiva. ¡Cuántos «ases» del balón tendrían que pasar a un reformatorio físico!” (Ruiz-Ferry, 1924, p. 467).

\subsection{La sistematización de un pensamiento divergente}

En este momento Juarros presentó Normas de educación sexual y física (1925), probablemente la obra más carismática del protagonista, que fue dedicada al padre de familia para servir de guía en el modo de educar a los hijos, con razones diáfanas de entender. Si bien la primera parte de la obra que compete a la educación sexual es expuesta bajo influencias del psicoanálisis, en la segunda parte se aborda una contundente oposición al modelo deportivo y a ciertas formas de entender la educación física. Primeramente, se ocupaba de trasmitir las aclaraciones conceptuales de la materia, incriminando el abuso desmesurado del deporte, el Olimpismo y los excesos del ejercicio gimnástico o acrobatismo; insistía en la necesidad de mostrar los dos términos, deporte y Educación Física, como antagónicos. El deporte era para Juarros un: 
medio de consumir gratamente el remanente de energía, no podía ser considerado como educación física, ni siquiera, un método de ella. Con el deporte no se adquiría el desarrollo armónico del organismo, todo lo contrario, una "desnivelación, desigualdad de unos músculos en perjuicio de otros. (Juarros, 1925, p. 130)

Como el deporte tenía por finalidad el récord, este se oponía y se salía de la educación física que perseguía, por el contrario, la salud. Así que Juarros denunció los abusos de la ejercitación gimnástica de aparatos y del acrobatismo, que comparaba con los deportes, puesto que ambos buscaban el mayor rendimiento, el exhibicionismo, el espectáculo y el lucro personal, sin la menor consideración higiénica y de salud. Asimismo, también se ocupó de criticar al Olimpismo, puesto que era la institución culpable de la desviación que la educación física estaba causando en los jóvenes. Para Juarros (1925, p. 137), el Olimpismo y los deportes eran "los mayores enemigos de nuestras generaciones españolas":

La obsesión del record de la marca, del campeonato, es un sentimiento que a toda costa debe evitarse en el alma del niño. Sus riesgos son tres: Narcisismo. Parasitismo. Desinteresamiento. (...) Por otra parte, olimpismo equivale a especialización, es decir, a predominio de determinadas masas musculares. Predominio traduce desequilibrio; desequilibrio, enfermedad ... Uno de los mayores enemigos de las nuevas generaciones españolas, es el olimpismo como el deporte; totalmente distintos ambos de la auténtica educación física. (Juarros, 1925, pp. 130-131)

En otro apartado, Juarros expuso las diferentes modalidades de educación física, a la vez que trataba la "guerra” ideológica entre las diferentes escuelas gimnásticas (Torrebadella-Flix y Domínguez, 2018b). Sobre ello indicaba unas normas básicas de lo que no debía hacerse y entre otros aspectos destaca: “e) El niño no debe dedicarse a ningún deporte antes de los doce años... g) El niño no debe estar bajo la dirección de un profesor de educación física que no conceda importancia primordial a las particularidades psicológicas del alumno” (Juarros, 1925, pp. 169-170). 


\subsection{Un compromiso de responsabilidad social}

En 1927, en una serie de seis artículos cortos en La Libertad -en la sección "La Higiene, la Medicina y la Salud”-, Juarros (1927a, 1927b) aclaraba conceptos y advertía de los riesgos de la práctica deportiva sin una adecuada condición física. Aludía a los muchos adolescentes mal alimentados y poco desarrollados que enfermaban por los sobreesfuerzos de querer emular a los ases del fútbol. Por otro lado, clarificó su posición: "No existe en mí enemiga alguna contra el balompié ni contra el deporte alguno. La tesis al servicio de la cual estuvo siempre mi pluma es ésta: No debe hacer deporte sino quien tenga condiciones para ello" (Juarros, 1927b, p. 6).

En este año, Juarros participó en un ciclo de conferencias de la Sociedad Peñalara de Madrid y se centró en "la psicología del deportista español”. Varios periódicos de la capital -El Imparcial y Heraldo de Madrid- trataron el tema (Juarros, 1927c, 1927d): "El deportista español piensa, por el contrario, que jugando al balompié se educa físicamente. Y piensa algo más. Piensa que realiza una misión de cultura. Este engreimiento somático tradúcese en ambiciones espectaculares" (Juarros, 1927c, p. 4).

Durante los años veinte, Juarros no paró de publicar artículos de opinión, impartir conferencias y, todo eso, sin desatender sus quehaceres profesionales y aficiones. No obstante, la Dictadura no se vanaglorió de las consideraciones de Juarros, probablemente por su radicalismo antideportivo y, en especial, por la fiebre futbolera del momento. Durante estos años se encargó de la dirección de la Escuela Central de Anormales. En un cursillo organizado por la Asociación de Maestros de Madrid expuso cuáles eran a su juicio las causas que en España existiese tan elevada población de niños anormales, y una de ellas era precisamente el error que se tenía al confundir la educación física con el deporte:

Los sensatos practican simultáneamente con el deporte una gimnasia compensatoria. Hay, en cambio, gentes tan desorientadas como un cartero conocido mío, que tras pasarse el día subiendo escaleras, en los ratos de ocio dedícase furiosamente al fútbol. [...] Créase así un tipo de hombres que no viven del balompié, pero a los que el balompié impide vivir de ninguna otra cosa, ebrios de egolatría, de vanidad. Tal actitud repercute 
forzosamente en las gentes de manera clarísima. El ideal no es Cajal ni Beethoven, sino Zamora y Mojardín. (Juarros, 1928a, p. 307)

Por otro lado, no fueron menos significativos los juicios de Juarros cuando pedía que en la educación moderna se estableciera la complicidad y la cooperación entre maestros y médicos. Se refería especialmente a la entrada del psicoanálisis en la escuela, una alternativa, decía, que todavía nadie había considerado por desconocimiento y gran aversión. Así mencionaba que la gente aún no se había dado cuenta de la trascendencia social que el psicoanálisis reportaba en el campo pedagógico (Juarros, 1929). Con lo cual, muchos niños sufrían el ser calificados por el maestro como inadaptables, desordenados, peligrosos, anormales, incapaces de estudiar, llegando incluso a indicar a la familia su encierro en un asilo o reformatorio. En cambio:

El maestro enterado empieza a fortalecer el espíritu del niño, le da tratamiento psíquico adecuado. El chico acabó por comportarse de modo totalmente normal. Este muchacho sin tratamiento adecuado y sin diagnóstico hubiera caído en el fondo de un asilo; de allí no. hubiera salido nunca. (Juarros, 1928b, p. 363)

Con la II República la situación fue diferente y Juarros retomó el protagonismo. En la revista Crónica se pedía que opinara sobre ¿Cuáles eran los seis problemas más urgentes que debía resolver el Gobierno provisional de la República? Juarros marcó que había que atender: $1^{\circ}$ Educación física, $2^{\circ}$ Educación sexual, $3^{\circ}$ Educación intelectual, $4^{\circ}$ Psiquiatría, $5^{\circ}$ Vida rural y $6^{\circ}$ Profilaxis. Sobre el primero manifestó: "Educación física es sinónimo de democracia orgánica. Desarrollo por igual. Armonía. Frente el deporte en su esencia especialización... Cada niño debe recibir la educación física apropiada a sus condiciones” (Marqués, 1931, p. 10).

Durante este período Juarros $(1933,1934)$ continuó en su cruzada personal "en pro de la noble educación física”, aconsejando a los padres de familia sobre "el arte de escoger deporte a los niños" y sobre la "higiene deportiva”, es decir, la práctica saludable del deporte sin riesgo. Efectivamente, Cruz y Martín, el redactor deportivo de Crónica, tomó partido por las posiciones de Juarros, por eso hacía también "una llamada a tiempo": 
En los pasados días se ha alzado la autorizada voz de don César Juarros ... [...]. El niño debe jugar; debe hacer, a lo más, una gimnasia educativa: debe acostumbrarse a vivir al aire y al sol, a retozar, a sentir la alegría de ganar a diario un trozo de su vida de hombre. Pero nada de ponerle al borde de una enfermedad por hacerle gozar de ese morboso deleite del triunfo, en una edad y con una capacidad corporal con las que todavía no puede entablar batallas. (Cruz y Martín, 1933, p. 30)

\section{LA VIGENCIA DE LAS IDEAS DEL DOCTOR JUARROS}

Parece altamente significativo que numerosas aportaciones $\mathrm{y}$ expresiones de Juarros siguen vigentes al cuestionarse aspectos y límites que la aplicación del deporte debe acoger. Numerosas y diversas autorías contemporáneas siguen ahondando en las problemáticas que el autor analizado ya planteaba hace un siglo, sirvan como ejemplo para alimentar una comparativa de referencias actuales.

Es por lo tanto crucial divulgar que en el deporte en sí mismo no educa de manera alguna, tampoco es depositario de valores, sino que sus efectos educativos dependen de los contextos e interacciones sociales determinadas (Cruz, Boixadós, Torregrosa y Mimbrero, 1996). Con lo cual, hoy, seguimos apreciando usos y conductas violentas en el deporte escolar, es decir, aspectos sociales y psicológicos que no nos gustan desde un enfoque pedagógico. Esto es lo que Juarros (1918, p. 34) llamó, hace ya 100 años, la obsesión por el record, el narcisismo y la "vanidad al fuerte y de despecho al débil”.

La historia del paradigma del deporte educativo más reciente sigue señalando problemáticas en los aspectos señalados por Juarros:

El deporte tendría que servir para enseñar a encajar las victorias tanto como las derrotas, y siempre respetando el contrario. A la postre, todo forma parte del proyecto educativo de la persona. Aprender a vivir superando las frustraciones, llevando la rivalidad solo al momento del juego. (Vizcarra, Macazaga y Recalde, 2006, p. 86)

Así, se observa como "estas conductas contrastan con los principios del fair play y la deportividad que deberían ser promovidos en el deporte escolar: diversión, juego limpio, compromiso, respeto, relaciones correctas, igualdad de oportunidades, rechazo de la victoria a cualquier precio, etc.” (Gairín, Muñoz, Castro y Díaz, 2014, p. 263). 
Es, por lo tanto, una problematización insistente e inacabada y quizás imposible, pero que se resiste a encontrar programas de formación deportiva que eduquen en valores ante la excesiva competitividad y la pérdida del tan presumido juego limpio (Iturbe y Elosúa, 2012). Hay que recordar sencillamente que para Juarros (1925), como también sostenía Hébert (1925), el deporte no tenía nada de educativo, sino que más bien deseducaba.

Se puede aquí observar actualmente la problematización del deporte sobre la salud:

El deporte escolar, que hoy día practica la mayoría de los jóvenes españoles, muchas veces, no conlleva un reconocimiento médico deportivo anterior a su práctica, por lo que nos induce a pensar que el deporte para jóvenes podría no ser un verdadero agente de promoción de la salud por lo menos desde una perspectiva controlada. (Pérez, Cortell, Suárez, Andreu, Chinchilla y Cejuela, 2008, p. 221).

También la necesidad de aplicar cambios en el contexto escolar para conseguir un mayor grado de inclusión. Y aquí cabría el "aplicar las normas del deporte escolar de forma modificada, flexible y dinámica buscando el máximo de participación independientemente del nivel de habilidad de los niños y las niñas” (Estrada, 2013, p. 489).

Hoy en día no es difícil visualizar conflictos, cuando en la Educación Física en las propuestas de actividades físico-deportivas se percibe el

exceso de individualismo, exceso de competitividad, falta de respeto entre iguales, poco nivel de socialización, rechazo y exclusión entre iguales por el nivel de condición física y de adquisición de habilidades y destrezas motrices -y la correspondiente desconfianza y frustración que ello conlleva. (Torrebadella-Flix y Domínguez, 2018a, p. 409).

Otra problemática añadida sería la comercialización que el deporte ha generado desde hace ya algunas décadas y su influencia en el ámbito escolar:

A pesar de que el deporte espectáculo trata de adornarse con estos valores morales y educativos, se trata de una compleja coartada ideológica-comercial para vender mejor el «producto». Lo cierto es que en dichos niveles el deporte se encuentra absolutamente profesionalizado y comercializado y lo único que realmente interesa en él es el triunfo, el 
éxito, el récord, en definitiva, el dinero que pueda generar. (Durán González, 1996, p. 109).

La visión y la necesidad de adaptación del deporte a las características evolutivas, contrastada con numerosos trabajos realizados sobre la historia de la psicología del deporte de la infancia, ya estaba expuesta por Juarros. Por lo tanto, este hecho fundamenta el recuperar su figura como pionero de la psicología del deporte, además cuando nada se ha expuesto sobre ello (Pérez y Estrada, 2015; Vilanou y Laudo, 2004).

Varios autores tratan sobre los peligros de los enfoques deportivos que se alejan de la vertiente educativa. Así, por ejemplo, Cruz, Boixadós, Valiente y Torregrosa (2001) señalan como causas relevantes del deterioro del fair play las cuatro siguientes:

Aumento de las recompensas económicas por el éxito en el deporte infantil y juvenil.- Valores, actitudes y comportamientos de entrenadores orientados al éxito en las competiciones.- Actitudes y conductas de los padres y espectadores durante los partidos.- Sistema de sanciones de algunos reglamentos que benefician la persona infractora. (Cruz, Boixadós, Valiente y Torregrosa, 2001, pp. 12-13)

Por su parte, Fraile (2004) advierte sobre el abuso tendencioso del deporte escolar por parte de las federaciones deportivas, que presionadas por la Administración se dirigen a la deriva de un modelo, en el que ganar se antepone a la participación y se reducen, por lo tanto, los valores pedagógicos de una educación integral -cognitiva, motriz, emocional y social- de los sujetos: "Los entrenadores utilizan modelos de enseñanza directiva basada en aprendizajes mecánicos, analíticos y dirigidos hacia la especialización, prematura, generando una clara división del trabajo preocupada por la eficacia del gesto y quedando al margen del disfrute personal" (Fraile, 2004, pp. 9-10).

En consecuencia, los ejemplos mediáticos que atentan el Fair Play y los valores educativos son constantes. Los problemas que actualmente tienen los profesionales de la Educación Física y el deporte escolar para contrarrestar los malos ejemplos de los mitos deportivos televisivos dan la razón a Juarros. En ningún sentido se duda de las posibilidades para desarrollar valores dentro del deporte, pero se constata que las dificultades para conseguirlo no son de tiempos actuales y vienen de hace décadas. 
La crítica al deporte se amplía finalmente con el olimpismo y en el peligro de que los niños se obsesionen con la marca y el récord y otros aspectos comentados. El narcicismo que provoca y el desinterés por los problemas nacionales hacen del deporte y del olimpismo los "enemigos de las nuevas generaciones españolas” según Juarros (1925, pp. 136-137) y, hoy, para Perelman (2014), se convierten en una plaga mundial de difícil solución.

De todos modos, Juarros aportó un primer campo epistemológico para profundizar en las cuestiones pedagógicas en donde la educación física pasaba a configurar una materia de educación en las múltiples relaciones de una sociedad compleja, con lo cual, en el fondo subyacía un enfoque holístico que hoy también es tema de reflexión, es decir, la "imposibilidad de hablar de Educación Física como una entidad autónoma, ajena a las otras maneras educativas” (Juarros, 1925, p. 232).

\section{REFLEXIONES FINALES}

En la historia de la educación física y el deporte en España la figura del Dr. Juarros es relevante. Este estudio preliminar, como se mencionó al principio, ha puesto al descubierto la contribución de este emblemático y hasta ahora desconocido propagandista de la educación y de la cultura física en general, entre otras muchas facetas. En este sentido, no solamente se ha resituado al personaje y su contribución, también se ha dilucidado parte del discurso que problematizó la educación física y el deporte en el primer tercio del siglo pasado. Todo ello ha sido posible a través de explorar la riqueza de la obra de este carismático autor que, implicado con los problemas sociales de su entorno, adoptó un compromiso de responsabilidad en el que expuso la divergencia de sus ideas ante un mundo cambiante y desafiante bajo el dominio del capitalismo moderno. Juarros trató de exponer su atrevida reflexión a la ciudadanía; eso sí, aportó un juicio razonado y crítico con el que probablemente muchos se mostraron disconformes, pero este juicio era necesario para confrontar y decidir posiciones y actitudes ante la vida.

Así, se confirma que la figura de Juarros representó en España la primera opinión académica que, desde la psicología social infantil y la criminología, manifestó una especial atención a la educación física y el deporte. Por lo tanto, Juarros atendió un incipiente discurso en torno a un campo científico en construcción y adoptó una posición lo suficientemente sólida para que figure como un adelantado en la 
psicopedagogía deportiva escolar. Además, se aprecia que la posición de Juarros no difiere mucho de cierto pensamiento crítico actual.

La obra de Juarros esconde interesantes aportaciones que pueden abrir nuevas miradas, ya sea desde la pedagogía, la criminología o la psicología, pero aquí solamente se ha considerado, a grandes rasgos, el que atañe a la educación física y el deporte; sin embargo, no hay duda de que su obra está abierta para emprender nuevas prospecciones.

\section{BIBLIOGRAFÍA}

Álvarez Peláez, R. (1988). El Instituto de Medicina Social: primeros intentos de institucionalizar la eugenesia (en España). Asclepio, 40, 343-358.

Cansinos, R. (1928, 7 de abril). Crítica literaria. El niño que no tuvo infancia... La Libertad, p. 6.

Coubertin, P. (1913). Essais de Psychologie Sportive. Lausana et Paris: Payot \& Cia.

Coubertin, P. (1925). Lecciones de pedagogía deportiva. Presentadas en el Instituto Olímpico de Lausana. La Escuela Moderna, 408, 695-702.

Cruz y Martín, A. (1933, 11 de junio). Una llamada a tiempo, Crónica, p. 30.

Cruz, J., Boixadós, M., Torregrosa, M., y Mimbrero, J. (1996). ¿Existe un deporte educativo?: papel de las competiciones deportivas en el proceso de socialización del niño. Revista de Psicología del Deporte, 5(2), 111-134.

Cruz, J., Boixadós, M., Valiente, L., y Torregrosa, M. (2001). Es perd el "fair play” i l'esportivitat a l'esport en edat escolar? Apunts. Educació Física i Esports, 64, 6-16.

Del Cura, M., y Huertas, R. (2004). Medicina y sexualidad infantil en la España de los años treinta. La aportación del psicoanálisis a la pedagogía sexual. Hispania, 64(218), 987-1001.

Diego Pérez, M. D. C., y González Fernández, M. (2014). La educación sexual en la escuela primaria: un intento frustrado de los eugenistas. Cuestiones de género: de la igualdad y la diferencia, 9, 158-191. 
Discóbolo (1919, 13 de febrero). La propaganda deportiva. Nuevas orientaciones. Madrid-Sport, p. 2.

Durán González, J. (1996). Deporte, violencia y educación. Revista de Psicología del deporte, 5(2), 103-111.

Estrada, J. (2013). La competición deportiva en las clases de Educación Física de la etapa primaria: su tratamiento como medio educativo. En J. Castejón, F. J. Giménez, F. Jiménez y V. López (coord.), Investigaciones en formación deportiva (pp. 473-492). Sevilla: Wanceulen.

Fraile, A. (2004). El deporte escolar en el siglo XXI: análisis y debate desde una perspectiva europea. Barcelona: Graó.

Gairín, J., Muñoz, J. L., Castro, D., y Díaz, A. (2014). Causas de la intolerancia en las competiciones deportivas escolares: Elaboración de un código de conducta. Revista de psicología del deporte, 23(2), 255-265.

Hébert, G. (1925). El sport contra la educación física. Barcelona: Mercantil.

Huertas, R., y Novella, E. (2013). Sexo y modernidad en la España de la Segunda República. Los discursos de la ciencia. Arbor, 189(764), 090. http://dx.doi.org/10.3989/arbor.2013.764n6013

Iturbe, L. M., y Elosúa, P. (2012). Percepción del fair play en deportistas infantiles y cadetes. Revista de psicología del deporte, 21(2), 253-259.

Juarros, C. (1916a, 4 de agosto). Al margen de un Congreso. Educación Física y Acrobatismo. El Liberal, p. 3.

Juarros, C. (1916b, 9 de agosto). Aledaños de un Congreso. Carácter y educación física. La Correspondencia de España, p. 7.

Juarros, C. (1916c, 14 de diciembre). El día médico. Las finalidades del Congreso de Educación Física. Hay que crear no traducir. El Día, p. 3.

Juarros, C. (1917, 22 de abril). El día médico. Los deportes en el Redhill. La educación física como medio de reforma. El Día, p. 4.

Juarros, C. (1918). Educación Física y moral del niño en la familia como preparación de su futuro desenvolvimiento integral. Madrid: Sociedad Española de Higiene, Imp. Artística Sáez Hermanos. 
Juarros, C. (1919, 15 de enero). Los deportes como causa de enfermedad. La Educación Física, p. 15.

Juarros, C. (1923, 23 de febrero). La elección de deporte. La Jornada Deportiva, p. 2.

Juarros, C. (1924, 26 de agosto). Hacia una higiene deportiva. Aire Libre, p. 1.

Juarros, C. (1925). Normas de educación sexual y física. Madrid: Renacimiento.

Juarros, C. (1927a, 2 de enero). Por la salud y la belleza I. El porqué. La Libertad, p. 6.

Juarros, C. (1927b, 16 de enero). Por la salud y la belleza II. Educación Física. La Libertad, p. 6.

Juarros, C. (1927c, 21 de mayo). Psicología del deportista español. El Imparcial, p. 4.

Juarros, C. (1927d, 25 de mayo). El doctor Juarros habla de Psicología del deportista español. Heraldo de Madrid, p. 11.

Juarros, C. (1928a, 1 de julio). La unión de médicos y maestros contra la anormalidad infantil. La Escuela Moderna, 442, pp. 301-310.

Juarros, C. (1928b, 1 de agosto). La unión de médicos y maestros contra la anormalidad infantil. La Escuela Moderna, 443, pp. 362-367.

Juarros, C. (1929). Los horizontes del psicoanálisis. Madrid: Mundo Latino.

Juarros, C. (1933, 7 de mayo). En pro de la noble educación física: El arte de escoger deporte a los niños. El Campeón, pp. 3-4.

Juarros, C. (1934, 24 de octubre). Hacia una higiene deportiva. Músculo y educación física son dos conceptos diametralmente opuestos en el deporte. La Tierra, p. 6.

Lévy, S. (2016). Delitos inconscientes. Psicoanálisis y teoría penal durante la Segunda República española, Culturas Psi, 6, 34-64. 
Marqués, F. (1931, 24 de mayo). Encuesta de Crónica. ¿Cuáles son, a su juicio» los seis problemas más urgentes que debe resolver el Gobierno provisional de la República? Crónica, p. 10.

Martínez Vargas, A. (1918). Discurso inaugural leído en la solemne apertura del curso académico de 1918 a 1919 ante el claustro de la Universidad de Barcelona (En Defensa de la Raza). Barcelona: Tip. la Académica de Serra y Russell.

Mosse, G. L. (2000). La imagen del hombre. La creación de la moderna masculinidad. Madrid: Talasa.

Noticias (1917, 21 de marzo). Gaceta de Instrucción Pública y Bellas Artes, pp. 189-190.

Orthous, M. H. (2015). La psicología deportiva de Pierre de Coubertin: Génesis, características, obstáculos. Materiales para la Historia del Deporte, Suplemento Especial II, 112-121.

P. P. (1919, 20 de febrero). La propaganda deportiva. Conferencia del Dr. Juarros. Madrid-Sport, p. 6.

Perelman, M. (2014). La barbarie deportiva. Crítica de una plaga mundial. Barcelona: Virus Editorial.

Pérez, E. A., y Estrada, O. (2015). Historia de la Psicología del Deporte. Apuntes de Psicología, 33(1), 39-46.

Pérez, J. A., Cortell, J. M., Suárez, C., Andreu, E., Chinchilla, J. J., y Cejuela, R. (2008). La salud en la competición deportiva escolar. Revista Internacional de Medicina y Ciencias de la Actividad Física y el Deporte, 8(31), 212-223.

R. S. (1913, 5 de mayo). Actualidad extranjera. El Congreso de Lausama. El Imparcial, pp. 1-2.

Revista de revistas (1900, 15 de julio). Revista Política y Parlamentaria, p. 13.

Ruiz-Ferry, R. (1917, 25 de marzo). Educación Física. Heraldo Deportivo, pp. 96-97. 
Ruiz-Ferry, R. (1924, 5 de noviembre). Atletismo. Heraldo Deportivo, pp. 465467.

Samblás, P. (2002). César Juarros y el tratamiento de la morfinomanía: ¿cura u ortopedia?. Frenia. Revista de Historia de la Psiquiatría, 2(1), 123-154.

Samblás, P. (2004). El Dr. César Juarros (1879-1942) y la Escuela Central de Anormales. En J. Martínez-Pérez, M. I, Porras, P. Samblás y M. Del Cura (coord.), La medicina ante el nuevo milenio: una perspectiva histórica (pp. 539-550). Cuenca: Ediciones de la Universidad de Castilla-La Mancha.

Samblás, P. (2008). El doctor César Juarros (1879-1942) y el diván: 'la psicoanálisis del repentismo'. En J. Martínez-Pérez, J, Estévez, M. del Cura, y L. Blas, (eds.), La gestión de la locura. Conocimiento, prácticas y escenarios (España, siglos XIX-XX) (pp. 507-526). Cuenca: Universidad de Castilla-La Mancha.

Sanz, M. (1913a, 3 de julio). Por la Educación Física. Mejoramos la raza. La Correspondencia de España, p. 6.

Sanz, M. (1913b, 29 de julio). Por la educación física. Mejoremos la raza. La Correspondencia de España, p. 4.

Torrebadella-Flix, X. (2017a). Filantropía, educación y fútbol: la obra benéfica de Max Bembo en Barcelona (1907-1922). Revista Internacional de Educación para la justicia social, 6(2), 177199. https://doi.org/10.15366/riejs2017.6.2.011

Torrebadella-Flix, X. (2017b). La historia de la educación física escolar en España. Una revisión bibliográfica transversal para incitar a una historia social y crítica de la educación física. Espacio, Tiempo y Educación, 4(1), 1-41. http://dx.doi.org/10.14516/ete.2017.004.001.76

Torrebadella-Flix, X., y Brasó, J. (2017). Barcelona y el problema de la educación física en la primera enseñanza a principios del siglo XX. Las Escuelas Catalanas del Distrito VI. Revista Brasileira de História da Educação, 17(2), 135-173. http://dx.doi.org/10.4025/rbhe.v17, n2.915

Torrebadella-Flix, X., y Domínguez, J. A. (2018a). El deporte en la educación física escolar. La revisión histórica de una crítica inacabada. Retos: Nuevas Tendencias de la Educación Física y el Deporte, 34, 403-411. 
Torrebadella-Flix, X., y Domínguez, J. A. (2018b). Las escuelas gimnásticas en España: un enfrentamiento técnico doctrinal en la educación física (18061936). Materiales para la Historia del Deporte, 17, 136-165.

Torrebadella-Flix, X., y Vicente-Pedraz, M. (2016). La gimnástica como dispositivo antionanista en la conformación de la educación física escolar en el siglo XIX en España. El nacimiento de una disciplina escolar. Movimento, 22(1), 99-114.

Torrebadella-Flix, X., y Vicente-Pedraz, M. (2017). En torno a los orígenes del fútbol como deporte escolar en España (1883-1936). De moda recreativa a dispositivo disciplinario. Educación Física y Ciencia, 19(1), e018. https://doi.org/10.24215/23142561e018

Torrebadella, X. (2011). Repertorio bibliográfico inédito de la educación física y el deporte en España (1800-1939). Madrid: Fundación Universitaria Española.

Torrebadella, X. (2012). El deporte contra la educación física. Un siglo de discusión pedagógica y doctrinal en la educación contemporánea. Movimiento humano, 4, 73-98.

Torrebadella, X. (2014). Regeneracionismo e impacto de la crisis de 1898 en la educación física y el deporte español. Arbor, 190(769): a173. http://dx.doi.org/10.3989/arbor.2014.769n5012

Torrebadella, X. (2016). España, regeneracionismo y deporte durante la I Guerra Mundial. Athenea Digital. Revista de Pensamiento e Investigación Social, 16(1), 237-261. doi:http://dx.doi.org/10.5565/rev/athenea.1501

Torrebadella, X. (2019). La Escuela Central de Gimnasia del Ejército de Infantería en Toledo (1919-1930). Textos y contextos en la configuración de la educación física y el deporte militar en España. Revista Universitaria de Historia Militar, 8(16), 182-206.

Vilanou, C., y Laudo, X. (2004). Emili Mira i els orígens de la psicologia de l'esport. Barcelona: Generalitat de Catalunya.

Vizcarra, M. T., Macazaga, A. M., y Recalde, I. (2006). Amb quin esport escolar somien les famílies? Apunts. Educació Física i Esports, 86, 97-107. 